\title{
Jovem e trabalho
}

\author{
CLEY SCHOLZ* \\ Maria do Carmo Brant de Carvalho \\ MARIA JULIA AZEVEDO \\ Wagner A. SAntos
}

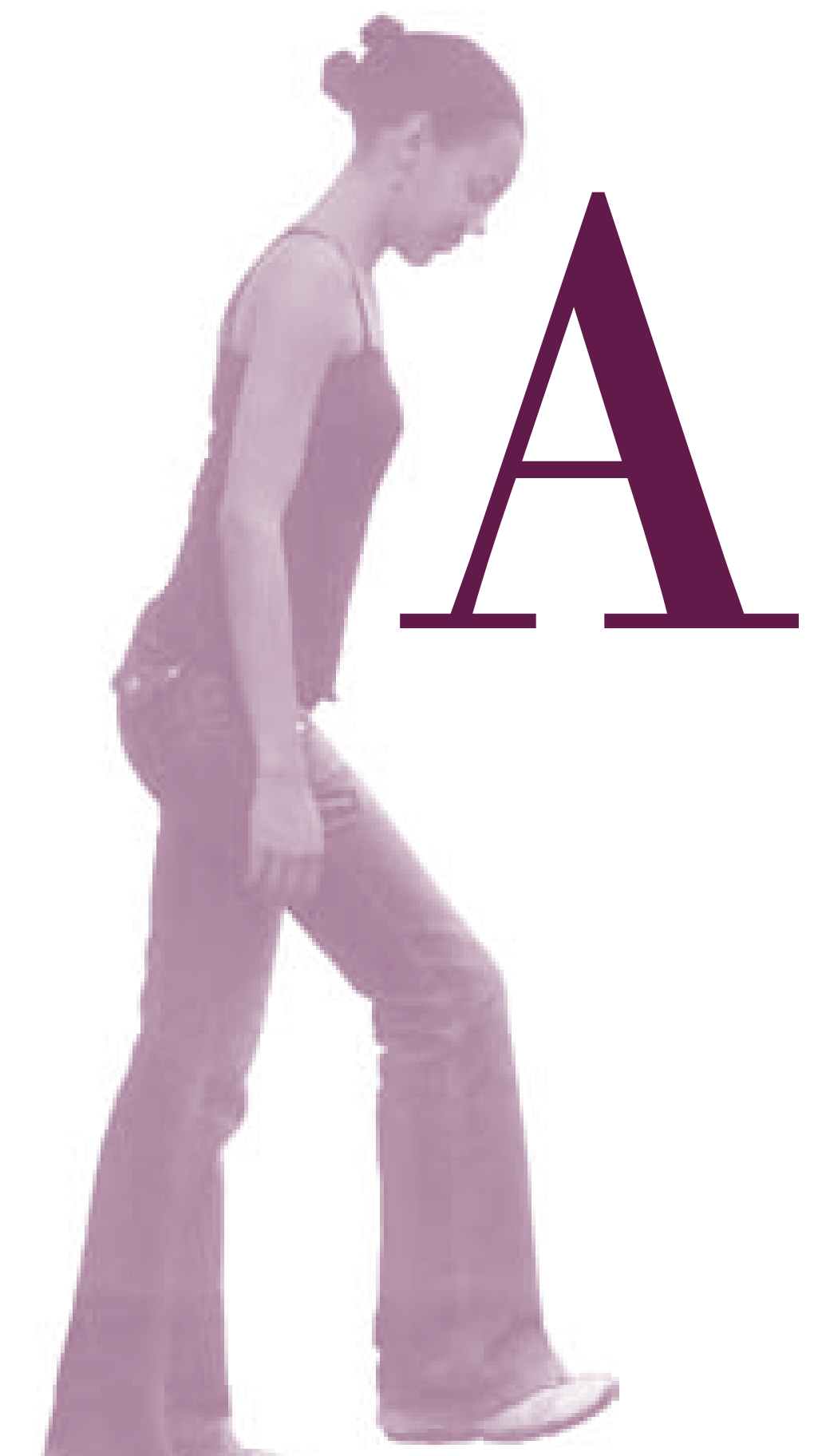

Atualmente, $46,6 \%$ dos desempregados brasileiros são jovens, segundo dados do Instituto de Pesquisa Econômica Aplicada (Ipea). São 35 milhões de brasileiros de 16 a 24 anos, a maior população jovem da história do Brasil, numa encruzilhada e sem perspectiva de saída: de um lado, a escola não os atrai. De outro, o mercado de trabaIho não os aceita. 0 problema torna-se mais grave diante da ineficácia dos programas oficiais de formação ou de incentivo ao ingresso do jovem no mercado de trabalho.

Nos últimos cinco anos, apesar do crescimento da economia e da redução do desemprego para a população em geral, o mercado de trabalho para o jovem piorou de forma preocupante. Hoje o desemprego chega a $19 \%$ entre os jovens de 15 a 24 anos de idade. Essa proporção é 3,5 vezes maior que a observada entre os adultos. Em 1995, a taxa de desocupação dos jovens não chegava ao triplo da dos adultos.

A disputa por oportunidades de emprego é perversa especialmente para os que não avançaram na formação escolar.

"Os 9 milhões de jovens brasileiros de 18 a 29 anos sem escolaridade básica, os mais de 800 mil que são

* Cley Scholz é Jornalista e Editor do Caderno de Economia do Jornal O Estado de São Paulo.

MaRIa do CARmo BRANT de CaRvalho é Doutora em Serviço Social pela Pontifícia Universidade Católica de São Paulo e Pós-Doutorada em Ciência Política pela École des Hautes Études em Sciences Sociales de Paris. Foi professora do Programa de Pós-Graduação em Serviço Social - PUC-SP, é autora de vários trabalhos publicados e atualmente é Coordenadora Geral do Centro de Estudos e Pesquisas em Educação, Cultura e Ação Comunitária (Cenpec)

MARIA JÚlIA AZEVEDo é psicóloga, mestre em educação (USP -SP) e Coordenadora da Área Educação e Comunidade do Cenpec.

WAgner dos Santos é Cientista Social, doutorando em política (PUC - SP), pesquisador do Núcleo de Estudos de Arte, Mídia e Política da PUC - SP e Coordenador do Programa Jovens Urbanos - Cenpec. 
analfabetos e os mais de 8 milhões que se evadiram, que desistiram da escola antes de completar o primeiro ciclo, são melancólica antecipação de que serão longos os anos das muletas sociais em que se escora o País. Se levarmos em conta que mais de dois terços deles vivem em áreas urbanas, a perspectiva fica pior ainda. Durante muito tempo, viver na roça era invocado como o fator causal da baixa escolaridade de crianças e jovens. Mas agora, no cenário oposto, fica a evidência de que o fracasso escolar está mais associado ao urbano e moderno que ao atrasado, mais ao novo que ao velho. Indício de que estamos construindo uma sociedade mutilada." (Souza Martins, 2008).

Em aproximadamente duas décadas, a máquina de escrever cedeu lugar ao computador e a um mundo bem mais complexo. A transformação ampliou infinitamente o conceito de analfabetismo.

Ainda na reflexão do sociólogo José de Souza Martins, professor da Faculdade de filosofia da USP, "analfabeto é também quem sabe ler e escrever, quem estudou mas não sabe pensar no cotidiano, sem as regras modernas de pensamento, quem não tem cultura básica que permita manejar um computador, ler um livro, ler um jornal, compreender a imagem que vê na televisão compulsória e invasiva, conhecer e respeitar os sinais e as regras de trânsito, os direitos do outro, a vital reciprocidade da sociedade moderna".

\section{Formação para o trabalho}

Para qualquer jovem, a entrada no mercado de trabalho marca o seu ingresso na vida adulta. No Brasil, há uma imensa maioria que precisa de um emprego por questão de subsistência da família e outros que sonham apenas com uma oportunidade de aprendizado, acesso ao lazer e à cultura com alguma autonomia financeira. Para todos eles, a formação é a chave para ingressar no universo do trabalho.

Nas últimas décadas, porém, o desemprego vem crescendo entre os jovens a ponto de se tornar um problema crucial para a sociedade. A situação frustra os jovens, que se sentem incapazes de alcançar uma condição econômica ao menos equivalente ao dos seus pais. E aumenta a sensação de deterioração social, já que é nítida a gravidade do problema da falta de oportunidades de realização pessoal e de obtenção de renda para o exército de jovens que se aproxima a cada ano da idade de começar a trabalhar.
A elevada taxa de desemprego na faixa de até 17 anos indica que grande parte das famílias brasileiras não tem condições de manter os jovens fora do mercado de trabalho até o fim do ensino médio. A dimensão crescente do fenômeno levanta dúvidas em relação às dificuldades cada vez maiores dos jovens para enfrentar a transição da escola para o trabalho.

Nos últimos 15 anos, a taxa de desemprego entre jovens cresceu sempre acima da média dos adultos. Em conseqüência, a proporção de jovens entre os desempregados ficou maior.

O problema é grave no mundo inteiro, mas muitos países conseguem reduzir o desemprego juvenil com políticas públicas voltadas para o emprego entre jovens. No Brasil, porém, a situação do emprego entre jovens mostra-se alarmante. A taxa de $46,6 \%$ de jovens desempregados é maior do que a do México (com 40,4\%), Argentina (39,6\%), Reino Unido (38,6\%), Suécia (33,3\%), Estados Unidos (33,2\%), Itália (25,9\%), Espanha (25,6\%), França (22,1\%), e Alemanha (16,3\%).

No mundo inteiro, a preocupação ganha dimensão, motivando iniciativas como os 'Objetivos de Desenvolvimento do Milênio', que levaram ao lançamento da Rede de Empregos para Jovens da Organização Internacional do Trabalho. Entre as alternativas discutidas para atenuar o problema, existem as políticas de formação profissional, de incentivo a contratações e normativas.

No Brasil, a criação de programas governamentais com esse propósito mostra-se generosa, mas os resultados não são animadores. Existem iniciativas nas áreas de formação profissional, com recursos do Fundo de Amparo ao TrabaIhador (FAT), políticas de incentivo oficial, como o programa primeiro emprego e políticas normativas, como a lei do aprendiz. 0 exemplo mais eloqüente foi o Primeiro Emprego, lançado pelo governo federal em 2003 e abandonado em 2007, depois de resultar na criação de apenas 15 mil postos de trabalho para jovens - $3 \%$ da meta inicial.

Dentre as várias causas do alto desemprego entre os jovens brasileiros, a falta de qualificação profissional é reconhecidamente uma das mais importantes. Mas os cursos públicos de educação profissional técnica, elogiados por sua qualidade, enfrentam uma grave deficiência. Segundo estimativa do Ministério da Educação, a oferta de vagas atende a apenas $11 \%$ da demanda potencial.

0 investimento em formação profissional, segundo um estudo do Ipea, é de eficácia questionável como for- 
ma de reduzir significativamente o desemprego juvenil. Isso porque o aumento do desemprego não se dá apenas entre os jovens e ocorre por causa da geração insuficiente de postos de trabalho para toda a população trabalhadora. Dessa forma, aprimorar as habilidades dos jovens provavelmente não significa garantia de espaço muito maior no mercado. Se isso ocorresse, seria em detrimento do emprego dos adultos, aumentando a concorrência por vagas. Para o Ipea, em um cenário de desemprego elevado, a formação profissional é apenas compensatória, ao reduzir a desigualdade no mercado quando é dirigida aos jovens de menor "empregabilidade".

Apesar de ineficaz em termos concretos para reduzir o desemprego juvenil, a formação profissional pode ajudar a limitar a rotatividade no emprego e abrir melhores possibilidades para a carreira profissional dos beneficiados.

Políticas de incentivo à oferta de vagas para jovens consistem basicamente em redução do custo para a contratação. Uma das formas é a criação de subsídio, que transfere para o Estado uma parte do custo salarial. Outra alternativa é a redução de encargos trabalhistas. O risco é o de que as empresas possam passar a contratar jovens com subsídio para substituir trabalhadores adultos. Nesse caso, o benefício seria apenas para a empresa, e não para o mercado de trabalho, pois os novos desempregados continuariam competindo com outros jovens.

No caso das políticas normativas, existem várias experiências de regulação de novas formas de contrato de trabalho temporário, em jornada parcial e com menos encargos, o que se assemelha aos subsídios para contratação. Também há propostas que fixam limites ao emprego de jovens, buscando orientar sua experiência profissional para a aprendizagem.

Em todos estes casos, as políticas servem mais para influenciar as características dos trabalhadores que buscam trabalho do que para a geração de ocupações.

A evidência de que a educação é insuficiente e ineficiente para preparar o jovem para o mundo contemporâneo aponta cada vez mais para a necessidade de uma nova diretriz educacional. Fica cada vez mais evidente que o mundo está mudando rapidamente, e o mercado de trabalho também, mas a escola não acompanha o ritmo da mudança. Ela parece incapaz de preparar o jovem para os desafios do mundo. Justo ela, que seria uma das poucas instituições que poderiam ajudá-lo nesta hora. Uma proposta, lançada pelo soci- ólogo José de Souza Martins, é a de que o ensino médio deveria permitir aos estudantes o acesso à sociologia básica que os capacitasse a compreender o outro e o diferente e, na mediação do outro, compreender a si mesmo. Segundo ele, quanto mais o País demorar a colocar esse meio de discernimento ao alcance dos jovens, mais se agravará o analfabetismo cultural que limita o alcance e empobrece as outras disciplinas do ensino médio.

Para o sociólogo, o debate dobre a educação no Brasil tornou-se um debate equivocado sobre emprego, quando deveria ser pensada como a preparação para a vida, para o sonho, para sempre e também para o emprego.

\section{Alguns números para refletir sobre a questão}

*Faltam profissionais qualificados para o mercado de trabalho. Em vários setores, há vagas, mas as empresas não conseguem preenchê-las. 0 déficit de profissionais qualificados e com experiência é mais relevante em determinados setores da indústria: química e petroquímica, produtos de transportes e mecânicos e extrativista mineral. Segundo o Ipea, falta mão-de-obra com qualificação e experiência para 123,3 mil vagas com carteira assinada abertas em 2007.

O mesmo estudo apontou que 207,4 mil trabalhadores qualificados deverão permanecer desempregados neste ano por falta de vagas suficientes nos setores econômicos para as quais esses profissionais estariam habilitados. O setor com a maior sobra de mãode-obra qualificada é o da construção civil, apesar do boom registrado na área. Na contabilidade geral do Ipea, o mercado de trabalho brasileiro teria um excesso de mão-de-obra qualificada de pouco mais de 84 mil profissionais. Eles são uma parcela dos 1,7 milhão de trabalhadores qualificados que foram ao mercado de trabalho em 2007.

*Entre os 34 milhões de jovens de 18 a 29 anos que moram nas cidades brasileiras, $21,8 \%$ não concluíram a oitava série - e 2,4\% são analfabetos.

Os dados são da Pesquisa Nacional por Amostra de Domicílios do IBGE. Em alguns estados, como Alagoas, a parcela dos que não concluíram o ensino fundamental chega a $46 \%$.

* Cinco em cada cem jovens com idade entre 15 e 20 anos são analfabetos, segundo as duas principais avaliações do ensino nacional, o Saeb e o Enem. Vivem em pequenos municípios rurais (60\%), quase sempre no Nordeste (65\%). 
*Enquanto fala-se de evasão escolar nos ciclos fundamental e médio, os dados dos cursos superiores mostram os efeitos da obrigação de escolha da profissão na idade entre 17 a 20 anos. De cada cem jovens que entram numa faculdade de engenharia, só 41 concluem esse curso. Metade dos que entram em escolas de administração desistem antes da formatura. Nas faculdades de direito, a porcentagem é de $38 \%$.

*Segundo o Dieese, jovens são hoje $46 \%$ dos desempregados, apesar de representarem apenas $25 \%$ da população economicamente ativa. Essa situação vem se agravando. 0 economista Cláudio Dedecca, da Unicamp, mostra que, em 1995, o desemprego atingia 13,9\% dos jovens de 16 e 17 anos. Em 2004, chegou a 24,2\%. O percentual de jovens de 15 a 17 anos fora da escola, medido pela Pnad (Pesquisa Nacional por Amostra de Domicílios), aumentou de 2003 para 2005, chegando a $18 \%$. Isso está diretamente relacionado a dois fatores medidos pelo MEC em seu Censo Escolar: evasão e reprovação. Ambas crescem no ensino médio.

*Uma tabulação feita pela pesquisadora Maria Lucia Vieira, do IBGE, mostra que $21,4 \%$ dos jovens das seis maiores regiões metropolitanas não estudam nem trabaIham. Para Adalberto Cardoso, diretor de ensino do Instituto Universitário de Pesquisas do Rio que pesquisa a transição de jovens da escola para o mercado, o índice de $18 \%$ de jovens fora da escola está perto de um limite estrutural. "O problema não é só da escola, nem é de vagas. Ele tem muito mais a ver com a estrutura da pobreza brasileira, já que a maior parte desses jovens que não estão estudando vem de famílias muito pobres, que precisam da mão-de-obra deles para compor a renda”, diz.

*Ruben Klein, pesquisador da Fundação Cesgranrio, vê o problema por outro ângulo: "Os jovens estão saindo da escola sobretudo porque não aprendem e acabam retidos na mesma série. Se estivessem progredindo, provavelmente conciliariam trabalho e estudo". Ele considera que é preciso pensar em políticas públicas que complementem a renda de famílias com jovens em idade escolar. O ministro da Educação Fernando Haddad concorda com a necessidade de bolsas para que os jovens de baixa renda permaneçam em cursos de formação e capacitação. Ele diz que o governo federal vem tentando fazer isso por meio dos programas ProJovem e Escola de Fábrica. Para ele, outro caminho é a aprovação de uma lei que torne obrigatório o estudo dos seis aos 17 anos. Hoje, ela vale dos seis aos 14 .

\section{Programa Jovens Urbanos}

Os jovens das periferias urbanas enfrentam um círculo vicioso em relação ao mundo do trabalho. Circulam entre ocupações temporárias, mal remuneradas e em geral informais. A situação dificulta a freqüência à escola e afasta ainda mais o jovem do mercado formal de trabalho. Este modelo tende a perpetuar as desigualdades e reproduzir a realidade que os jovens herdaram de seus pais. Para esta situação, os programas tradicionais de qualificação profissional apresentam modestos resultados, segundo especialistas. Esse tipo de intervenção apenas retarda, ou retira o jovem temporariamente da condição de quem procura trabalho e não encontra. (Castro e Aquino, 2008. p.46). São formações rápidas que fortalecem a posição desqualificada em que o jovem se encontra.

Como capacitar jovens da periferia das grandes $\mathrm{ci}$ dades para o mercado de trabalho? Se eles são a maioria entre os desempregados, e vivem em áreas onde existem pouquíssimas oportunidades, por onde começar a tarefa?

Com base nestas indagações o programa desenhado propõe encontros significativos com diferentes operadores sociais: a Cidade, as Culturas em ação nas metrópoles e as Tecnologias contemporâneas, privilegiando a ação combinada desses agentes na formação dos jovens participantes. Fomenta sua inserção nos múltiplos territórios que compõem a vida das metrópoles. Através de práticas de circulação na cidade, o Programa propicia encontros ativos com potências movimentadas na cidade, promove a expansão de relações juvenis, concretizando usufruto de direitos de bens simbólicos e materiais que as cidades oferecem.

Ao entrarem em contato com a multiplicidade cultural em ação nas cidades e com diferentes modos de vida (além dos seus próprios), os jovens ampliam suas capacidades de pensar e agir sobre si mesmos e na cidade. Por outro lado, imersões em aspectos e questões urbanas contemporâneas sustentam novos desempenhos juvenis, em especial no mundo do trabalho e nos territórios onde mantêm vínculos.

A elaboração de produtos e projetos de intervenção potencializa as subjetividades juvenis, pois os jovens são desafiados a atuar em contextos das cidades e a construir projetos compondo perspectivas individuais e sociais. Ainda, por meio da produção, jovens experienciam atos de criação e exercitam a partilha social. 
Por último, aposta é que a qualificação das relações juventude e cidade, juventude e tecnologia, juventude e cultura contribua para a diminuição das situações de vulnerabilidade juvenil no campo escolar, profissional, público, relacional, das artes.

As relações institucionais mobilizadas pelo Programa sustentam-se numa perspectiva de ação pública em rede e pela necessidade de legitimidade de suporte institucional e político às ações de intervenção junto ao público juvenil. É assim que o programa caracteriza-se por um arranjo institucional composto por parcerias com órgãos públicos, empresas privadas ou públicas de economia mista e organizações do terceiro setor. Seus objetivos específicos são:

- Ampliar a circulação dos jovens na cidade, garantindo acesso às culturas urbanas e suas tecnologias;

- Ampliar conhecimentos para qualificação e acesso ao mundo do trabalho;

- Apoiar a produção de projetos de intervenção juvenil;

- Contribuir para a permanência e reintegração ao sistema escolar, além da vinculação a novos processos formativos.

\section{Os jovens falam sobre seu mundo de trabalho'}

Um grupo de nove jovens participantes do Programa foi convidado a levantar algumas idéias de como estão vendo, vivenciando e enfrentando questões do mundo do trabalho na periferia da maior cidade do País - o que o trabalho ensina, para que serve, qual é a relação entre o jovem e o trabalho?

Nas respostas a seguir, os jovens expressam com suas próprias palavras a visão do universo profissional a partir dos debates em grupo. A leitura serve de reflexão para todos aqueles que se preocupam com o futuro de milhões de jovens brasileiros que vivem uma difícil realidade em áreas onde faltam opções de lazer, cultura e trabalho e sobram problemas sociais e urbanos. São vítimas das metrópoles brasileiras e das desigualdades, não conseguindo por isso mesmo elaborar e perseguir metas mais consistentes como trabalhadores.

\section{Trabalho é}

\footnotetext{
experiência, nele você aprende e ensina.

responsabilidade, fazer o que tem que fazer.

uma forma de sobreviver, pois todos tem que trabalhar para ter o seu ganho.

uma atividade que exige paciência e união. Não dá para fazer só o que quer.

uma atividade na qual já está definido e organizado o que se vai fazer, o que se pode fazer e o que pode ser dito.

uma obrigação, pois eu tenho que me manter. Mas, não é só obrigação, pode ser também satisfação.
}

\begin{tabular}{|l|l|l|l|l|}
\hline $\begin{array}{l}\text { Idade atual } \\
\text { dos Jovens }\end{array}$ & O que fez no primeiro trabalho & $\begin{array}{l}\text { Com quantos anos teve } \\
\text { o primeiro trabalho }\end{array}$ & Sexo & Uma coisa que aprendeu \\
\hline 18 & $\begin{array}{l}\text { Fabrica de brinquedo - pintar } \\
\text { brinquedos }\end{array}$ & 16 & Feminino & $\begin{array}{l}\text { Fazer rápido, porque recebia } \\
\text { por produção }\end{array}$ \\
\hline 18 & \begin{tabular}{l} 
Supermercado - ajudante geral \\
\hline 17
\end{tabular} & 16 & Masculino & Controlar a raiva \\
\hline 18 & Cuidar dos sobrinhos & 15 & Feminino & Expressar-se melhor \\
\hline 18 & Orientador em estádio de futebol & 17 & Masculino & $\begin{array}{l}\text { Relacionar-se com pessoas } \\
\text { diferentes }\end{array}$ \\
\hline 17 & $\begin{array}{l}\text { Lava rápido - limpeza interna dos } \\
\text { veículos }\end{array}$ & 17 & Feminino & Ser mais rápida e responsável \\
\hline 18 & Doméstica e Babá de 3 crianças & 14 & Feminino & $\begin{array}{l}\text { Responsabilidade no cuidado } \\
\text { com as crianças }\end{array}$ \\
\hline 19 & Reciclar cartela de bingo - em casa & 15 & Feminino & $\begin{array}{l}\text { Responsabilidade com metas } \\
\text { diárias }\end{array}$ \\
\hline 18 & Lan House e Locadora - atendente & 16 & Masculino & Paciência com os clientes \\
\hline
\end{tabular}




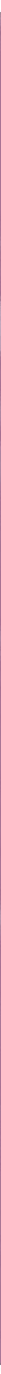

Agregado às definições eles refletiram sobre as características de alguns trabalhos, identificando os componentes de produção, renda, mercado e legalidade.

Trabalho pode ser em casa, na escola... Todo mundo tem trabalho de diferentes formas.

Tem trabalho que é emprego e tem emprego que não tem trabalho.

Trabalho que é todo dia é emprego. Trabalho é saber fazer alguma coisa: varrer, cozinhar... Também pode ser emprego, porque se recebe dinheiro com isso.

Emprego é quando alguém precisa de outra pessoa para fazer um trabalho, mas não é só uma coisa de união, há dinheiro envolvido. Em Brasília, há trabalho também, há os corruptos, mas há quem trabalha.

Roubo e trafico pode ser considerado trabalho? Trabalho desonesto também é trabalho? Trabalho desonesto é menos trabalho do que aquele que é honesto?

Os jovens conversaram também sobre as finalidades e motivações para trabalhar.

Há quem goste de trabalho para poder mandar nos outros.

Há quem trabalhe por necessidade e não goste do que faz - necessidade pela obrigação de manter a família (meu pai é motorista, o trabalho para ele é a vida, mas hoje o que ele faz é outra coisa, ele tem um serviço. É triste).

Há também casos em que a pessoa não gostava do que fazia, mas com o tempo, passa a gostar.

A gente pode "se dar bem", evoluir trabalhando com o que não gosta (ganhar mais, ser bom, ganhar outros cargos).

O trabalho pode ser não só para ganhar dinheiro, mas uma forma de 
viver a vida. Tem um monte de gente que trabalha com o que gosta. Algumas pessoas trabalham por prazer e satisfação e ainda ganham dinheiro.

Nossa discussão começou a ser desenvolvida a partir da questão financeira. Achamos que todos os que trabalham tentam ter uma situação financeira estável e crescente.

Foi então que vimos que nem todos trabalham para isso, mas por necessidade de uma vida social (conhecer e conviver com outras pessoas). Nem todas as pessoas de classe alta convivem com as pessoas de classe média ou baixa, o trabalho é uma oportunidade para isto. Como temos que trabalhar, nem todos trabalham com o que gostam, mas com o que podem. Se trabalhássemos com aquilo de que gostamos, mesmo ganhando menos, seríamos mais felizes.

\section{Imagino}

ter uma oportunidade aonde eu possa aprender e obter experiência. que no trabalho é preciso correr atrás dos seus objetivos. fazer uma faculdade para obter um bom emprego. participar de uma dinâmica na esperança de ser aprovada para a próxima etapa. Ou mesmo não sendo aprovada, sonhar em ter outras oportunidades para aprender o que for necessário.

fazer arquitetura. Casar com a minha namorada que fará engenharia e construirmos nossa casa. Só não vou trabalhar com esporte, porque não vou ganhar dinheiro.

Com este repertório de entendimentos esses jovens parecem afirmar que o trabalho é uma contingência não chegando a reconhecê-lo como possibilidade de expressão de si no mundo, ou melhor, mediação para se compartilhar o mundo. 0 trabalho é mais um meio de assegurar subsistência. É, igualmente, instrumento para obter relativa possibilidade de segurança e até gozo.

Trabalhar, mais do que cumprir ordens e ser controlado é adquirir experiência, compartilhar conhecimentos e evoluir. Nesta percepção encontra-se possivelmente o que mais o seduz no mercado informal: a liberdade e a casualidade.

Os jovens têm consciência da sua dificuldade para enfrentar o disputado mercado de trabalho o que não os impede de sonhar com a possibilidade de um dia conquistar um espaço de realização profissional, sem abrir mão de com isso obter satisfação pessoal. 0 jovem da periferia vê no trabalho a possibilidade de obter experiência e responsabilidade. Ele acredita que cursar uma faculdade poderia facilitar o acesso ao mercado, mas alimenta a esperança de ser aprovado na próxima entre- vista para um emprego. Mesmo diante de todas as dificuldades, acha que é preciso lutar e ter confiança em si mesmo para alcançar seus objetivos.

Os jovens finalizaram sua reflexão avaliando que o Programa Jovens Urbanos contribuiu para que construíssem novas visões sobre trabalhar. Um dos participantes resume a conclusão do grupo: Antes do PJU eu pensava em trabalhar para ajudar financeiramente a mim e a minha família. Agora eu continuo querendo isso, mas estou escolhendo um caminho, vendo que posso caminhar com as minhas próprias pernas, fazer uma coisa que gosto e também ajudar a minha família e, pensar em construir a minha.

\section{NOTAS}

1 Participaram da conversa sobre trabalho: Meridiana Camila Romero, Cleyton de oliveira, Leandro dos Santos, Roelson ferreira de vasconcelos, Sheila Angélica Pereira, Mario Sergio Evangelista da Silva, Rodrigo de Cassia Cala do, Vandeilma de Melo Silva, Nubia Alves da Silva, Talita Rodrigues Todao, Suzana Lucas Gonçalves.

\section{REFERÊNCIAS}

Ação Educativa. Notícias. Cláudio Dedecca fala sobre saídas para o desemprego juvenil Disponivel na Internet: http://www.acaoeducativa.org.br/portal/in dex.php?option=com_content\&task=view\&id=642. 03 de junho de 2008 .

DIEESE. A ocupação dos jovens nos mercados de trabalho metropolitanos. Estudos e Pesquisas. Ano 3 - № 24 - setembro de 2006

IPEA - Instituto de Pesquisa Econômica Aplicada. AQUINO, Luseni \& CASTRO Jorge A. (orgs.) JUVENTUDE E POLÍTICAS SOCIAIS NO BRASIL. Texto Para Discussão No 1335 . Brasília, abril de 2008

Souza Martins J. Os novos analfabetos da modernidade. Jornal O Estado de S. Paulo . Suplementos. ALIÁS. Domingo. 27 de Janeiro de 1008.Versão Impressa. Disponível na Internet: http://www.estadao.com.br/suplementos/not_sup115788,o.htm

Rede ANDI. Evasão escolar e desemprego crescem entre jovens. Disponível na Internet: http://www.redandi.org/verPublicacao.php5?L=ES\&id=2428\&idp ais $=3$. Acesso em 05 de junho de 2008. (extraído da Folha de S. Paulo - SP, Luciana Constantino e Antônio Gois, 01/10/2006)

Casa da Juventude Pe. Burnier. Evasão e desemprego crescem entre jovens. Disponivel na Internet: http://www.casadajuventude.org.br/index.php?op tion $=$ content\&task=view\&id=1162\&ltemid=0. Acesso em 05 de junho de 2008. Retirado da Folha de São Paulo On Line (01/10/2006) 